\title{
Cochlear Implant Merits in Patients with Meniere's Disease
}

\author{
Mohamed Salah Elgandy ${ }^{1,2 *}$ \\ ${ }^{1}$ Department of Otolaryngology-Head and Neck Surgery, Zagazig University, Egypt \\ ${ }^{2}$ Department of Otolaryngology-Head and Neck Surgery, University of lowa, lowa City, USA
}

*Corresponding author: Mohamed Salah Elgandy, Department of Otolaryngology-Head and Neck Surgery, University of lowa, lowa City, USA, E-mail: mohamedsalahibrahimsaleh-elgandy@uiowa.edu

Received: 24 May, 2019 | Accepted: 26 Jun, 2019 | Published: 29 Jun, 2019

Citation: Elgandy MS (2019) Cochlear Implant Merits in Patients with Meniere's Disease. J Surg Open Access 5(2): dx.doi.org/10.16966/24700991.182

Copyright: (c) 2019 Elgandy MS. This is an open-access article distributed under the terms of the Creative Commons Attribution License, which permits unrestricted use, distribution, and reproduction in any medium, provided the original author and source are credited.

\begin{abstract}
Meniere's disease is a chronic inner ear disease characterized by fluctuating sensorineural hearing loss, recurrent vertiginous attacks, tinnitus with aural fullness. Whether hearing loss is secondary to natural progressive course of disease or due to interventions, noticeable number of patients with Meniere's disease has unilateral non-serviceable hearing. So, cochlear implantation provides hope for those patients not only for hearing rehabilitation but also its positive effect on other non-auditory symptoms of Meniere's disease. Our article aims to review the beneficial effects of implanting patients with Meniere's disease regarding their hearing gain as measured by standard audiometric testing and discuss the effect of implantation on auditory and vestibular outcomes.
\end{abstract}

Keywords: Meniere's disease; Hearing loss; Cochlear implant; Surgical and audiological outcome

\section{Introduction}

Meniere's Disease (MD) is an idiopathic disease of the inner ear characterized by cochlear and vestibular symptoms including Sensorineural Hearing Loss (SNHL), tinnitus, vertiginous attacks, and sensation of aural fullness [1]. Etiology of MD is unknown, but there is strong relation between endolymphatic hydrops and increased inner ear pressure of membranous labyrinth [2]. Currently, it is proven that hydrops is not always associated with $\mathrm{MD}$ and should thus not be considered the main cause of its symptoms. Recent studies are based on the notion that MD is multifactorial as it may be the common endpoint of a variety of anatomic or physiologic conditions, including ischemic conditions or even an autoimmune disease [3]

Diagnosis of MD is based upon using the clinical guidelines of the American Academy of Otolaryngology-Head and Neck Surgery Committee on Hearing and Equilibrium (AAO-HNS CHE); these guidelines are focusing on a checklist of signs and symptoms [4].

Clinically, MD course is variable among patients. Some patients reported severe vertigo with minimal hearing loss, while others primarily report hearing loss with mild vertigo. Others could be affected by auditory symptoms and vertigo equally [5].

Early in MD, SNHL starts unilateral and fluctuates, primarily affecting low frequencies then high ones. With disease progression, hearing loss starts to stabilize with moderate to severe sensorineural up to profound in advanced cases [6]. Development of the later secondary to bilateral MD is relatively rare, but should occur. It was estimated that about $1-6 \%$ of patients develop severe to profound bilateral SNHL because of the natural progressive course of MD [7].
Studies showed that Cochlear Implantation (CI) can provide a solution because of challenges met with fitting MD patients with hearing aids. These difficulties include the patient's unilateral fluctuating hearing loss, arising audiometric configuration, reduced dynamic range, and reduced word-recognition scores (i.e., patients have word-recognition scores lower than predicted based upon the duration, configuration and magnitude of hearing loss). Presence of any of these obstacles cause difficulties for proper fitting of hearing aid and pave the way for CI [8].

\section{Candidacy for CI in Meniere's Disease Patients}

As MD presented by a group of auditory and vestibular symptoms, patients who have severe to profound SNHL would practically be an excellent CI candidate. That includes patients with bilateral, end-stage $\mathrm{MD}$ or those with unilateral MD and contralateral hearing loss caused by other diseases [9].

However, practically, CI still not approved by the United States Food and Drug Administration (FDA) for unilateral hearing loss, so patients with unilateral MD and non-affected hearing in the other ear do not match FDA criteria candidacy. Nowadays, there is a strong evidence that CI for patients with unilateral SNHL is associated with encouraging audiological results [10] but that is out of discussion in our article.

To make a decision and counsel patients with MD regarding CI role, we should take into account previous surgical history of patients to rule out a candidacy. Many authors initially believed that patient's with previous labyrinthectomy either chemical or surgical were not 
CI candidates due to cochlear nerve trauma, cochlear fibrosis, and ossification which could result from surgery. However, some studies proved that following surgery, the cochlea could maintain its spiral ganglion cell populations and could be tested and stimulated with transtympanic promontory testing which was first described by House WF, et al. [11] suggesting that patients could gain benefits from CI even they were having labyrinthectomy in the past.

Chen DA, et al. [12] reported that patients who had undergone labyrinthectomy still have spiral ganglion cells in their postmortem temporal bones.

Otte J, et al. [13] stated that patients with $\mathrm{MD}$ and even labyrinthectomy had a significant population of spiral ganglion cells and could gain benefit from electrical stimulation.

Kartush JM, et al. [14] reported a study in which promontory stimulation was tested in patients who had previously undergone either labyrinthectomy or CI. They found that both groups gave the same response and time interval following labyrinthectomy (1 month to 18 years) had no effect on the results of stimulation. These initial studies helped some authors to pave the way for further exploring CI gains in MD patients with prior labyrinthectomy.

\section{Evaluation Protocol}

\section{Pre-operative evaluation}

Counseling: Preoperative counseling with a detailed discussion about CI benefits, alternatives, risks, and postoperative complications as hematoma, wound infection, loss of taste and facial nerve injury. The possibility of poor implant response (or non-stimulation) should be issued in details. Patients who will undergo simultaneous labyrinthectomy and CI, counseling should be done regarding their postoperative vertigo which could last from weeks to months [10].

Surgical: Detailed history taking, with complete head, and neck examination and past history of any surgical operations.

Audiological: Complete audiometric evaluation both bone and air conduction pure tone thresholds and speech perception testing should be performed. Patients who will undergo labyrinthectomy and CI as one stage surgery, vestibular testing is mandatory to evaluate vestibular integrity on the other side.

Radiological: Magnetic Resonance Imaging (MRI) should be done to exclude retrocochlear pathology especially in unilateral MD with asymmetric sensorineural hearing loss; MRI also is beneficial in evaluating cochlear nerve integrity especially in patients who had undergone vestibular nerve section. Finally, MRI could provide us with some information regarding cochlear ossification or fibrosis together with Computerized Tomography (CT) [15].

\section{Surgical planning}

Generally patients are classified into 2 different groups: patients with $\mathrm{MD}$ and hearing loss secondary to natural progressive course of the disease or any intervention (other than labyrinthectomy): the second group is those who had undergone labyrinthectomy for vertigo control with resultant profound sensorineural hearing loss.

In the first group of patients, standard CI surgery through a postauricular transmastoid approach, posterior tympanotomy is performed; lateral semicircular canal and incus identification with caution to avoid the facial nerve injury, drilling of facial recess gives access to posterior tympanotomy with round window visualization. Once ideal exposure of the round window is in progress, its bony overhang carefully drilled with a $1 \mathrm{~mm}$ drill for better exposure of its membrane in preparation for electrode insertion [10].

In the second subset of patients, there is different surgical consideration. When performed simultaneously (CI and labyrinthectomy), most authors prefer to identify and expose round window by doing early posterior tympanotomy before labyrinthectomy because doing labyrinthectomy first could alter the anatomy when surgical removal of the lateral semicircular canal is done.

Hansen MR, et al. [16] reported in their study ten patients with stage IV MD, based on the 1995 American Academy of Otolaryngology-Head and Neck Surgery (AAO-HNS) guidelines, all of them had undergone labyrinthectomy with $\mathrm{CI}$ as one stage surgery. They noted that hearing was improved. According to their preference, they performed one stage surgery in patients with severeto profound SNHL and uncontrollable vertigo attacks for several reasons. These include fewer side effects associated with anesthesia and other surgical procedure. Also, the resultant tissue scarring or even cochlear ossification which could obscure further implantation due to prior surgical labyrinthectomy [17], although this is not a traditional response [18]. Finally, simultaneous surgery reduces the time of hearing loss and help patients to communicate quickly as CI performance is correlated with a duration of hearing loss [19].

MacKeith SA, et al. [20] described in their study 2 patients who had undergone labyrinthectomy and CI as one stage for severe secondside $\mathrm{MD}$ in the only hearing ear and they observed that hearing was improved with additional control of patients Ménière's attacks.

Heywood RL, et al. [21] reported 2 female patients with hearing loss which was non-hearing aid fitted with recurrent attacks of severe vertigo despite a trial of conservative management; they underwent labyrinthectomy and $\mathrm{CI}$ as one stage procedure. Both patients showed complete relief of vertigo together with speech perception improvement in a quiet environment and increased the ability to hear in noisy places.

The effectiveness of post-labyrinthectomy (sequential CI) in MD had been issued, especially if there is a lag period between two procedures. There were several contraindications to $\mathrm{CI}$ in patients who had undergone surgical labyrinthectomy. For example, neural degeneration versus retentions in patients with the previous labyrinthectomy as removal or degeneration of these structures can lead to poorer results with sequential labyrinthectomy however several studies demonstrated intact spiral ganglion neurons after surgery [12-14].

The second issue regarding sequential CI in patients with $\mathrm{MD}$ and previous labyrinthectomy is structural changes in both cochlea and vestibule. After surgery, obliteration of the vestibule by fibrous and bony tissues accumulation and the cochlea might become ossified; that could lead to difficult surgery and improper electrode insertion [22]. However, Osborn HA, et al. [23] reported a study with successful CI and improvement of hearing in noise test score from $0 \%$ pre-operatively to $60 \%$ at six months in patients who had bilateral labyrinthectomy procedures performed 21 years ago for uncontrollable Meniere's attacks.

Thedinger BA, et al. [24] reported a study on a patient who had ipsilateral labyrinthectomy 15 years ago for controlling intractable attacks of MD and later he developed profound sensorineural hearing loss on the other ear due to vestibular schwannoma. Successful implantation was done and the patient's hearing was improved.

Facer GW, et al. [25] reported a case of successful CI 18 months after labyrinthectomy for vestibular schwannoma. 
So as a conclusion, there is no consensus as to whether or not labyrinthectomy should be performed sequential or simultaneously, the one stage surgery has been found to decrease cochlear fibrosis and/ or ossification with decreasing the lag period experienced by patients having profound sensorineural hearing loss especially in those with residual hearing preoperatively [21].

\section{Outcomes after Surgery}

\section{Hearing}

Recent studies showing that patients with $\mathrm{MD}$, who underwent $\mathrm{CI}$, can show hearing outcomes equivalent to CI recipients who have severe to profound SNHL due to causes other than MD [26]. Prediction of individual's performance after $\mathrm{CI}$ is different according to years of deafness, age at which implantation was issued, motivation, the primary mode of communication and rehabilitation [27].

Lustig LR, et al. [28] reported a study on 9 patients who had severe to profound bilateral sensorineural hearing loss caused by MD and were implanted. They found a significant improvement in hearing outcome based on testing of hearing at 1 year and continued to improve with time. Furthermore, they concluded that patients with MD appeared to outperform equally like adults with postlingual hearing loss without MD.

Hansen MR, et al. [16] studied 10 patients with stage IV MD, based on the 1995 American Academy of Otolaryngology-Head and Neck Surgery (AAO-HNS) guidelines, all of whom underwent simultaneous labyrinthectomy with CI All patients noted that hearing outcome was improved.

Fife TA, et al. [7] found significant postoperative improvement in the mean sentence testing following implantation from $22.8-77.0 \%$ in 10 patients with $\mathrm{MD}$ who underwent $\mathrm{CI}$.

Mick P, et al. [29] did a comparison between 20 patients with "definite" MD, as outlined by the AAO-HNS guidelines that had undergone $\mathrm{CI}$ with matched controls and concluded that there were no differences in the change of sentence recognition scores between groups.

McNeil C, et al. [30] described a patient with bilateral sensorineural hearing loss with unilateral MD who had undergone bilateral CI; they noted that fluctuation of hearing is recurring postoperatively in $\mathrm{MD}$ ear following CI.

Samy RN, et al. [31] observed in their study that a group of patients with MD who had CI developed post-implantation fluctuation of hearing, suggesting that hydrops might cause bulging of scala media or affect spiral ganglion populations neurons.

Hearing fluctuations both subjective and implant stimulating threshold hearing is still unclear. Theoretically, once the CI electrode array is in place after surgery, there are some exacerbations in the hydropic state within the cochlea, and that should have no effect on the implant's performance. One mechanism for fluctuations in hearing may be that hydrops might cause bulging of scala media together with resultant alteration in the position of electrode and that may cause fluctuation in hearing experienced by some patients [32].

Another hypothesis to explain fluctuation is that hydrops could affect the afferent or spiral ganglion neurons directly through altering their responses to current spread by cochlear electrodes. Nadol JB, et al. [33] described cadaveric temporal bone of a patient with unilateral $\mathrm{MD}$, in whom there was no difference in the hair cells number or spiral ganglion populations on the MD side and another side but he discovered that there was marked decrease in population of afferent nerve fibers endings and afferent synapses at the base of both inner and outer hair cells in the ear with MD as compared with the other ear and that support the later theory.

\section{Vestibular}

Hansen MR, et al. [16] stated that all patients in their study $(n=10)$ had complete relief from their vertiginous attacks and were considered as class $\mathrm{A}$ at their last follow-up visit together with subjective improvement in their tinnitus. The authors preferred going for simultaneous labyrinthectomy and CI.

Fife TA, et al. [7] reported in their study $(n=10)$ that patients had an 8 times decrease in their vertiginous episodes after CI. Two patients of them experienced improvement of aural fullness; four patients noticed that tinnitus improved, and three patients experienced fluctuation of hearing. So, they concluded that CI could provide hearing rehabilitation for patients with $\mathrm{MD}$, with positive effects on both vertigo and tinnitus.

Doobe G, et al. [34] studied outcomes of 5 patients with unilateral MD who underwent simultaneous labyrinthectomy and CI. All patients experienced no improvement in their symptoms following CI, but using the Dizziness Handicap Inventory, all patients noticed 6 weeks postoperative, there was an improvement in the functional outcome compared with preoperative. Most of them remained free of symptoms by 6 months, and thus demonstrated that the Dizziness Handicap Inventory was improved in comparison to the preoperative one.

McRackan TR, et al. [5] found that most patients who were having active symptoms of MD of CI time experienced significant improvement in their symptoms post CI.

Mukherjee P, et al. [35] found that 12 of 22 ears (55\%) in their study had vestibular disturbance post $\mathrm{CI}$ and were able to localize symptoms to the ipsilateral ear. Four had acute vertigo or unsteadiness that resolved in less than 2 weeks, two had Benign Paroxysmal Positional Vertigo (BPPV), two had constant vestibular disturbance, two had recurrent non-positional vertigo, and two had delayed onset non positional vertigo many months after surgery. So they concluded that Patients with MD undergoing CI only may experience vestibular dysfunction which may cause long-term concerns.

\section{Conclusion}

Patients who receive $\mathrm{CI}$ for the rehabilitation of severe to profound SNHL due to MD are able to achieve significant improvement in their hearing levels comparable to the gain experienced by others without MD who undergoes CI. By introducing CI electrode into the cochlea near to the endolymphatic space in patients with MD neither seems to negatively alter the natural history of vestibular function nor exaggerates the auditory symptoms in CI candidates who have MD. Although some patients may still have fluctuations of their hearing following CI with occasional negative concerns on vestibular symptoms especially in ears with proper vestibular functions, others noticed improvement in hearing, vertigo, aural fullness, and tinnitus. So more studies and research in that area should be addressed in order to weight the benefits of hearing against the risk of vestibular problems in some patients. According to my point of view together with current studies, CI stills an excellent option for auditory rehabilitation of patients with MD who are candidates for surgery. 


\section{References}

1. Committee on Hearing and Equilibrium (1995) Committee on Hearing and Equilibrium Guidelines for the Diagnosis and Evaluation of Therapy in Meniere's Disease. Otolaryngol Head Neck Surg 113: 181-185.

2. Hallpike CS, Cairns H (1938) Observations on the pathology of Meniere's syndrome (Section of Otology). Proc R Soc Med 31: 13171336.

3. Berlinger NT (2001) Meniere's disease: new concepts, new treatments. Minn Med 94: 33-36.

4. Alexander TH, Harris JP (2010) Current Epidemiology of Meniere's Syndrome. Otolaryngol Clin North Am 43: 965-970.

5. McRackan TR, Gifford RH, Kahue CN, Dwyer R, Labadie RF, et al. (2014) Cochlear implantation in Meniere's disease patients. Otol Neurotol 35: 421-425.

6. Mancini F, Catalani M, Carru M, Monti B (2002) History of Meniere's disease and its clinical presentation. Otolaryngol Clin North Am 35: 565-580.

7. Fife TA, Lewis MP, May JS, Oliver ER (2014) Cochlear implantation in Meniere's disease. JAMA Otolaryngol Head Neck Surg 140: 535-539.

8. Valente M, Mispagel K, Valente LM, Hullar T (2006) Problems and solutions for fitting amplification to patients with Meniere's disease. J Am Acad Audiol 17: 6-15.

9. Morgan M, Flood L, Hawthorne M, Raje S (1999) Chemical labyrinthectomy and cochlear implantation for Meniere's disease-an effective treatment or a last resort? J Laryngol Otol 113: 666-669.

10. Hunter JB, O'Connell BP, Haynes DS (2016) Cochlear implantation in Meniere's disease. Oper Tech Otolayngol Head Neck Surg 27: 205209.

11. House WF, Brackmann DE (1974) Electrical Promontory Testing in Differential Diagnosis of Sensori-neural Hearing Impairment. Laryngoscope 84: 2163-2171.

12. Chen DA, Linthicum FH Jr, Rizer FM (1988) Cochlear histopathology in the labyrinthectomized ear: Implications for cochlear implantation. Laryngoscope 98: 1170-1172.

13. Otte J, Schunknecht HF, Kerr AG (1978) Ganglion cell populations in normal and pathological human cochleae. Implications for cochlear implantation. Laryngoscope 88: 1231-1246.

14. Kartush JM, Linstrom CJ, Graham MD, Kulick KC, Bouchard KR (990) Promontory stimulation following labyrinthectomy: Implications for cochlear implantation. Laryngoscope 100: 5-9.

15. Martens C, Csillag A, Davies M, Fagan P (2013) Cochlear implantation after selective vestibular nerve section. J Laryngol Otol 127: 311 313.

16. Hansen MR, Gantz BJ, Dunn C (2013) Outcomes after cochlear implantation for patients with single-sided deafness, including those with recalcitrant Meniere's disease. Otol Neurotol 34: 1681-1687.

17. Swartz JD, Mandell DM, Faerber EN, Popky GL, Ardito JM, et al. (1985) Labyrinthine ossification: etiologies and CT findings. Radiology 157: 395-398.
18. Osborn HA, Yeung R, Lin VY (2012) Delayed cochlear implantation after surgical labyrinthectomy. J Laryngol Otol 126: 63-65.

19. Rubinstein JT, Parkinson WS, Tyler RS, Gantz BJ (1999) Residual speech recognition and cochlear implant performance: effects of implantation criteria. Am J Otol 20: 445-452.

20. MacKeith SA, Bottrill LD, Ramsden JD (2014) Simultaneous labyrinthectomy with cochlear implantation in patients with bilateral Ménière's disease. Ann Otol Rhinol Laryngol 123: 485-489.

21. Heywood RL, Atlas MD (2016) Simultaneous cochlear implantation and labyrinthectomy for advanced Meniere's disease. J Laryngol Otol 130: 204-206.

22. Wareing MJ, O'Connor AF (1997) The role of labyrinthectomy and cochlear implantation in Meniere's disease. Ear Nose Throat J 76: 664-672.

23. Osborn HA, Yeung R, Lin VY (2012) Delayed cochlear implantation after surgical labyrinthectomy. J Laryngol Otol 126: 63-65.

24. Thedinger BA, Cueva RA, Glasscock ME $3^{\text {rd }}$ (1993) Treatment of an acoustic neuroma in an only-hearing ear: case reports and considerations for the future. Laryngoscope 103: 976-980.

25. Facer GW, Facer ML, Fowler CM, Brey RH, Peterson AM (2000) Cochlear implantation after labyrinthectomy. Am J Otol 21: 336-340.

26. Vermeire K, Brokx JP, Wuyts FL, Cochet E, Hofkens A, et al. (2005) Quality-of-life benefit from cochlear implantation in the elderly. Otol Neurotol 26: 188-195.

27. Waltzman SB, Fisher SG, Niparko JK, Cohen NL (1995) Predictors of postoperative performance with cochlear implants. Ann Otol Rhinol Laryngol Suppl 165: 15-18.

28. Lustig LR, Yeagle J, Niparko JK, Minor LB (2003) Cochlear implantation in patients with bilateral Ménière's syndrome. Otol Neurotol 24: 397-403.

29. Mick P, Amoodi H, Arnoldner C, Shipp D, Friesen L, et al. (2014) Cochlear implantation in patients with advanced Meniere's disease. Otol Neurotol 35: 1172-1178.

30. McNeill C, Eykamp K (2016) Cochlear implant impedance fluctuation in Meniere's disease: A case study. Otol Neurotol 37: 873-877.

31. Samy RN, Houston L, Scott M, Choo DI, Meinzen-Derr J, et al. (2015) Cochlear implantation in patients with Meniere's disease. Cochlear Implants Int 16: 208-212.

32. Linthicum FH Jr, Fayad J, Otto SR, Galey FR, House WF (1991) Cochlear implant histopathology. Am J Otol 12: 245-311.

33. Nadol JB Jr, Thornton AR (1987) Ultrastructural findings in a case of Meniere's disease. Ann Otol Rhinol Laryngol 96: 449-454.

34. Doobe G, Ernst A, Ramalingam R, Mittmann P, Todt I (2015) Simultaneous labyrinthectomy and cochlear implantation for patients with single-sided Meniere's disease and profound sensorineural hearing loss. Biomed Res Int 2015: 457318.

35. Mukherjee P, Eykamp K, Brown D, Curthoys I, Flanagan S, et al. (2017) Cochlear Implantation in Ménière's Disease with and without Labyrinthectomy. Otol Neurotol 38: 192-198. 